\title{
Survey of Gastrointestinal Parasite of Cattle and Goat Slaughtered At Trans Amadi Abattoir, Port Harcourt-Rivers State
}

\author{
Abah, A.E., Ebong, N.E. \\ Department of Animal and Environmental Biology, Faculty of Science, University of Port Harcourt PMB 5323 \\ Port Harcourt 50001, Rivers State, Nigeria
}

\begin{abstract}
This work was to survey gastrointestinal parasites of cattle and goat slaughtered at Trans Amadi abattoir in Port-Harcourt. A total of 100 faecal samples of the ruminants were examined comprising of 50 cattle and 50 goats. Formol-ether concentration technique was used for sample analyses and examined with microscopically. The data obtained were subjected to simple statistical analysis using percentages to determine the prevalence rate in both ruminants studied. The result showed that 28(56.0\%) of cattle and 23(46.0\%) of the goat were infected with gastrointestinal parasites. The infection was slightly higher in the cattle than the goat though the difference was not statistically significant $(P>0.05)$. Among the cattle, the organisms identified were Haemonchus contortus,Trichuris globulosa,Trichostrongylus columbriformis Monezia benedeni and Fasciola gigantica. The most prevalent organism was Haemonchus contortus 34.0\%, followed by Monezia benedeni 14.0\%, while Trichuris globulosa $2.0 \%$ and Fasciola gigantica $2.0 \%$ were the least. The organisms identified from the goat on the other hand include; Haemonchus contortus, Trichostongylus columbriformis, Monezia benedeni, Taenia species. The most dominant organism was Taenia species 16\%, followed by Monezia benedeni $14.0 \%$, and while Trichostongylus columbriformis was the least dominant. The result showed a moderately high prevalence of gastrointestinal parasite during the period of study. Abattoir survey is an excellent way of determining the prevalence of ruminant parasitic disease as to control the disease through regular de-worming, proper feeding and good sanitary measures.
\end{abstract}

Keywords: Gastrointestinal, parasite, Prevalence, Abattoir, Cattle, Goat. Port Harcourt

\section{Introduction}

Helminthic infection is a cosmopolitan disease affecting ruminants, especially in places of poor hygiene and feeding (Faye et al 2003). Mortality of animals caused by parasitic diseases might not be frightening but the effects on livestock efficiency as well as its' impact on human health are considerably high. Helminth infections of ruminants are mostly caused by nematodes such as Trichuris species, Strongyliodes species, Capillaria species, Ostertagia species; cestodes such as Moniezia species, Taenia species; and trematodes such as Fasciola gigantica, Dicrocoelium species (Zahid et al 2005). In the intestinal tract, these parasites lay minute eggs that are found in the animal's feaces. The eggs undergo development into larvae. Within some days especially during warmer period, further development of the larvae to an infective stage occurs. While on the ground, the larvae can migrate from the feacal sample to other grasses close by or the animals can step on their dung; thereby enhancing further spread of the larvae. The animals however get infected through the ingestion of the contaminated grass. These parasites are associated with infections resulting in great economic losses to farmers which is apparent through morbidity in severe cases and loss of weight, abortion, infertility, reduction in food utilization, reduced meat and milk production in chronic cases (Bariajaya et al 1995).Also according to Regassa et al., (2006), it brings about a reduction in work capacity, spontaneous culling, high rate of treatment, and reduction in the market value of infected animals and in severe cases, death of animals. The most important predisposing factors of helminth infections are grazing habits, climate, poor nutrition, immunological level of the ruminant, vector, presence of intermediate host, and the number of infective larvae and eggs in the environment (Siddiki et al., 2001).Intestinal parasite in ruminants have been carried out by other researchers world over. Rehbein et al., (2013) conducted an investigation in European cattle and goat and discovered several parasites. Anderson (2000), Besier and love (2003) reported Haemonchus contortus, Trichostrongylus species and Ostertagia circumcinta to parasitize cattle and goat in Australia. In Nigeria, Biu and Eteng (2001) indicated a high prevalence of parasite infestation on University of Maiduguri Research Farm while Edosomwan and Shoyemi (2012) in Southern Nigeria discovered species of Trichuris, Capillaria, Monieiza, Strongyloides and Dicrocoelium infecting cattle and goat. Only few of these studies have been conducted in Southern part of the Country and there is a dearth of information in Rivers State. The present study was undertaken to investigate the gastrointestinal parasites among the frequently slaughtered animal-cattle and goat in Trans Amadi abattoir in Port Harcourt Rivers State. 


\section{Description of Study Area}

\section{Materials And Methods}

This study was carried out in Trans Amadi area of Port Harcourt. Trans Amadi is a thousand-hectare (2,500-acre) industrial area, with a diverse residential neighbourhood in the city of Port Harcourt. Situated at $4^{\circ} 48^{\prime} 53^{\prime \prime} \mathrm{N}$ latitude and $7^{\circ} 2^{\prime} 14^{\prime \prime} \mathrm{E}$ longitude, the neighbourhood supports a strong industrial sector and is thus considered to be a major trading zone in Port Harcourt. The Trans Amadi Abattoir is the major and the biggest abattoir located in Port Harcourt, Rivers State with about a hundred cattle slaughtered on daily basis. Cattle and goats slaughtered in this abattoir are often obtained from different cattle rearing regions of Nigeria -mainly Northern Nigeria and neighbouring countries like Niger. Hence, this abattoir serves as a good source of sentinel survey for diseases (including helminthic infections) from different regions of Nigeria and beyond. Again, because of its location and large number of animals slaughtered, this abattoir serves as a major source of meat consumed in the city.

Ethical clearance: Ethical clearance was obtained from the Research management unit of the University of Port Harcourt.

\section{Sample Collection}

The abattoir was visited early on each day of collection and a total of 100 fresh feacal samples were obtained from the rectum of the ruminant using disposable glove into clean labelled leak proof sample bottle. Samples were taken to the Parasitology and Public Health Laboratory of the Department of Animal and Environmental Biology, University of Port Harcourt for examination. Each feacal sample was examined for helminth parasites using the Formol-ether technique according to Cheesbrough,(1999) and Ballweber (2001).

Samples were analysed using the Formol-ether concentration technique. About $1 \mathrm{~g}$ of the sample was emulsified in $10 \%$ formol saline which was then filtered into a test tube using gauze. It was then centrifuged for ten minutes at 4000 revolution per minute (rpm), it was decanted allowing the sediment only. $3 \mathrm{ml}$ of formol saline was added to the sediment, shaken vigorously, thereafter $1 \mathrm{ml}$ of formol ether was added and again shaken to have a good mixture. The mixture was then centrifuged at 4000 revolutions per minute for ten minutes. With a plastic bulb pipette, the feacal debris from the side of the tube was loosened and the tube inverted to decant the supernatants. The tube was returned to its upright position and the fluid from the side of the tube, allowed to drain to the bottom. The deposit was mixed by just a little shake. A drop of the sediment was placed on a grease free slide; covered with a cover slip and examined under the microscope using $\times 10$ and $\times 40$ objectives. Lugol's iodine was also used as a stain.

\section{Egg Identification}

Parasites eggs were identified based on morphological features described by Soulsby (1982) while the data obtained from the microscopic examination of the sample were recorded on a sheet for both cattle and goat for easy interpretation.

\section{Result}

Out of the total of one hundred ruminants comprising 50 cattle and 50 goats examined, the result showed that $28(56.0 \%)$ of cattle and $23(46.0 \%)$ of the goat were infected with gastrointestinal parasites. The infection was slightly higher in the cattle than the goat though the difference was not statistically significant $(\mathrm{P}>0.05)$ (Table 1). Among the cattle, the organisms identified were Haemonchus contortus, Trichuris globulosa, Trichostrongylus columbriformis Monezia benedeni and Fasciola gigantica. The most prevalent organism was Haemonchus contortus $34.0 \%$, followed by Monezia benedeni $14.0 \%$, while Trichuris globulosa $2.0 \%$, and Fasciola gigantica 2.0\% were the least (Table 2). The organisms identified from the goat on the other hand include; Haemonchus contortus, Trichostongylus columbriformis, Monezia benedeni, Taenia species. The most dominant organism was Taenia species $16 \%$, followed by Monezia benedeni $14.0 \%$, while Trichostongylus columbriformis was the least dominant (Table 3).

Table 1: Prevalence of Gastrointestinal Parasites in Cattle and Goats at Trans Amadi abattoir Port Harcout

\begin{tabular}{|l|l|l|l|}
\hline Animals & No.Examined & No.Infected & \%infected \\
\hline Cattle & 50 & 28 & 56 \\
\hline Goat & 50 & 23 & 46 \\
\hline Total & $\mathbf{1 0 0}$ & $\mathbf{5 1}$ & $\mathbf{5 1}$ \\
\hline
\end{tabular}


Table 2: Prevalence of Gastrointestinal parasitesin cattle at the Trans AmadiAbatoir in Port Harcourt

\begin{tabular}{|l|l|l|}
\hline Gastrointestinal Parasite & No of Cattle infected $(\mathbf{N}=\mathbf{5 0})$ & \% Infected \\
\hline Haemonchus contortus & 17 & 34 \\
\hline Trichuris globulosa & 1 & 2 \\
\hline Trichostrongylus columbriformis & 2 & 4 \\
\hline Monezia benedeni & 7 & 14 \\
\hline Fasciola gigantica & 1 & 2 \\
\hline Total & $\mathbf{2 8}$ & $\mathbf{5 6}$ \\
\hline
\end{tabular}

Table 3: Prevalence of Gastrointestinal parasites in goat at the Trans AmadiAbatoir in Port Harcourt

\begin{tabular}{|l|l|l|}
\hline Gastrointestinal Parasite & No of Goat infected $(\mathbf{N}=\mathbf{5 0})$ & \% Infected \\
\hline Haemonchus contortus & 6 & 12 \\
\hline Trichostongylus columbriformis & 2 & 4 \\
\hline Monezia benedeni & 7 & 14 \\
\hline Taenia species & 8 & 16 \\
\hline Total & $\mathbf{2 3}$ & $\mathbf{4 6}$ \\
\hline
\end{tabular}

\section{Discussion}

This study showed that cattle and goat slaughtered at Trans- Amadi abattoir were infected with a wide variety of gastrointestinal parasites; with an overall prevalence of $56 \%$ in cattle and $46 \%$ in goat. The prevalence in cattle is slightly higher in range from studies conducted by Biu and Eteng (2001)in University of Maiduguri farm in which the prevalence of parasites in cattle was 51.3\%. From this study, it was observed that more gastrointestinal parasites were found to have infected more cattle than goat. This result is similar to that conducted by, Edosomwan and Shoyemi (2012) in Benin City. This could be due to the fact that the cattle are mostly raised under extensive agricultural system, where they undergo free-range grazing where small droppings from the animal degenerates rapidly, thus releasing worm larvae which in turns increases the rate of pasture contamination bringing about a high prevalence rate when compared to that of the goat which are mostly raised under intensive system.

The possible reason for the differences observed in the prevalence of the gastrointestinal helminth parasites recorded in this study and that recorded by other researchers may be because of the differences in locations, management practices (Regassa et al., 2006 and Waruiru et al., 1993) and period of investigation. The research work was carried out during rainy season which is known to be the period with high infectivity rate due to higher humidity and other optimal environmental conditions which enhances transmission in the tropics. This is similar to a research conducted by Belem et al., (2001) who observed a high incidence of parasite in the season. This might be because of an increase in humidity content that favours the development of the eggs of these parasites. Also, during this season there is high rate of pastoral growth, which brings about an increase in contact rate between the parasites and the host.

Parasites identified in this study include Haemonchus species, Trichuris species, Trichostrongylus species, Moniezia species, Fasciola species and Taenia species. It is similar to that identified by Rehbein et al., (2013) and Biu and Eteng., (2001). Parasites identified in the present study belong to the group of parasites known to cause production disease. Unfortunately, majority of the parasites were found in both cattle and goat for example Haemonchus contortus which is a blood sucking nematode have been found to result in production losses and even death in untreated animals (Marshall et al., 2012). Their presence confirms the fact that they are the most important pathogen of cattle and goats in the tropical and subtropical environments. Also co- infection of many of these parasites have been reported with Haemonchus contortus and Trichostrongylus spp most prevalent and highly pathogenic in livestock (Tan et al., 2014). These parasites constitute the main source of health issues related with livestock. The presence of these parasites in the animal may cause anaemia, retarded growth. Heavy infestation can result in weight loss, reduced productivity, restlessness and even death. The control of diseases caused by these parasites is somewhat difficult because its epidemiology is complex and the prevalence rate changes drastically with environmental factors.

In Nigeria, despite the enormous contribution made by the livestock sector to the economic wellbeing of the citizenry, little or no attention is given to it and is therefore faced with many problems such as parasitic disease infestation. In conclusion, this study showed a moderately high rate of gastrointestinal parasite in both ruminants studied which poses health risks to humans and therefore the need for regular de-worming of the animals, health education and proper sanitary measures including the use of Personal Protective Equipment should be encouraged in the abattoir 


\section{References}

[1] Anderson R.C (2000) Nematode Parasites of Vertebrates. Their Development and Transmission. $2^{\text {nd }}$ edition. Wallingford, Oxon OX10 8DE, UK: CAB International; 2000

[2] Ballweber L.R (2001). Veterinary Parasitology (Practical Veterinarian).(S.P.Messonniered.). Butterworth-Heinemann Publication. USA.

[3] Bariajaya, D; Estuningsh, E.S; Darmono, M.R; Knox, M.; Stoltz, D.R. and Wilson, A.J. (1995). The use of wormala in controlling gastrointestinal nematode infection in sheep under traditional grazing management.Indonesia Journal HmuTermakdanveterineer. 13: 49-55.

[4] Belem, A.M.G; Ouedraogo, O.P; and Bessin R.(2001). Gastrointestinal nematodes and cestodes of cattle in Burkina Faso. Biotechnology Agronomy Social Environment5(1), 17-21.

[5] Besier R.B and Love S.C.J (2003). Anthelmintic resistance in sheep nematodes in Australia: the need for new approaches. Australian Journal of Experimental Agriculture 43:1383-1391.

[6] Biu,A.A. and Eteng, F.O. (2001). Some parasites causing diarrhoea amongst kid goats in Maiduguri, Nigeria. In: Proceedings of the 6th Annual Conference of Animal Science Association of Nigeria. September 17th -19th, 2001 University of Maiduguri Convocation Square. Pp. 232-233.

[7] Cheesbrough M (1999). District Laboratory Practice in Tropical Countries.Part 1.Low price edition, Cambridge University Press. Cambridge. Pp 196-198.

[8] EdosomwanE.U.andShoyemi O.O (2012). Prevalence of gastrointestinal helminth parasites of cattle and goats slaughtered in Benin City, Nigeria-Department of Animal and Environmental Biology, Faculty of Life Sciences, University of Benin; African Scientist Vol 13, No 2. Nigerian Society for Experimental Biology.

[9] Faye D, Leak S, Nouala S, Fall A, Losson B, and Geerts S (2003). Effects of Gastrointestinalhelminthinfections and plan of nutrition on the health and productivity of (West African Dwarf Sahelian) goat crosses in The Gambia.Small Ruminant Research ;50:153-161. doi: 10.1016/S0921-4488(03)00108-1.

[10] Marshall,R. Gebrelul,S . Gray L. and Ghebreiyessus ,Y (2012) Mixed Species Grazing of Cattle and Goats on Gastrointestinal Infections of HaemonchusContortus. American Journal of Animal and Veterinary Sciences 7 (2): 61-66.

[11] Regassa, F; Sori, T; Dhuguma, R. and Kiros, Y.(2006). Epidemiology of

[12] gastrointestinal parasites of ruminants in western Oroma, ethiope. InternationalJournal of Applied Research of Veterinary Medicine. 4(1): 51-57.

[13] Rehbein,S.; Baggott, D.G.; Johnson, E.G.;Kunkle, B.N.; Yazwinski, T.A.;Yoon, S.; Cramer, L.G.andSoll, M.D.(2013) Nematode burdens of pastured cattle treated once at turnout with eprinomectin extended-release injection. Veterinary Parasitology. 192, 321331.

[14] Siddiki, A.Z; Uddin M.B; Hasan M.B; Hossain, M.F; Rahman, M.M; Das, B.C; Sarker, M.S and Sharkhuu T (2001).Helminths of goats in Mongolia. Veterinary Parasitology; 101:161-169. doi: 10.1016/S0304-4017(01)00508-8.

[15] Soulsby, E.J.L.(1982). Helminths, arthropods and protozoa domesticatedanimals. BailliereTindall, London. 233pp.

[16] Tan,T.K. Panchadcharam,C . Low, V.L. Lee,S.C. Ngui, R. SharmR.S.K.and Lim Y.A.L. (2014)Co-infection of Haemonchuscontortus and Trichostrongylusspp. among livestock in Malaysia as revealed by amplification and sequencing of the internal transcribed spacer II DNA region

[17] BMC Veterinary Research 2014 10:38 DOI: 10.1186/1746-6148-10-38

[18] Waruiru R.M.; Weda E.H.; Munyua W.K.(1993). Seasonal occurrence of gastrointestinal helminthes of cattle in Kiambu District, Kenya.In: Proc. of the 2nd Seminar on the DANIDA funded RHRP in Nairobi, Kenya, January 18-21.

[19] Zahid, I.A;Latif, M; and Baloch, K.B (2005). Incidence of endoparasites in exotic cattle calves. Pakistan veterinary Journal 25 (1): 47-48. 